\title{
Professional Training and Support of Student-Teachers at Schools: A View from Britain and Russia
}

\author{
Diana R. Sabirova ${ }^{1}$ \\ ${ }^{1}$ Kazan (Volga Region) Federal University, Kazan, Russia \\ Correspondence: Diana R. Sabirova, Kazan (Volga Region) Federal University, 420008, Kazan, Kremlyovskaya \\ Street, 18, Russia. E-mail: dianasab@mail.ru
}

Received: June 15, 2015 Accepted: June 24, 2015 Online Published: June 30, 2015

doi:10.5539/jsd.v8n7p214 URL: http://dx.doi.org/10.5539/jsd.v8n7p214

\begin{abstract}
The paper investigated urgent problems of modern educated society, which puts great expectations on school teachers - powerful formal guides of a new generation. Therefore it places a great emphasis on the proper training and support of student-teachers so that to determine their successful introduction into a challenging profession of a teacher. Demonstrating a considerable success in this field, Great Britain and Russia, however, face a number of challenges multiplied by the necessity to achieve a long-term goal of entering the European educational space. The aim of the research is to collect and analyze the most successful practices operated in the Russian and British teacher-training academic majors to enhance the future teacher's training and support worldwide. To meet the goals of the research the author mostly applied the descriptive method for observation and processing the investigated material as well as collecting, analyzing and synthesizing the information on teacher-training education in Great Britain and Russia. The analytical material is supported with the illustrations from the author's experience of a practice school teacher and a professor at Teacher-Training University for more than 20 years. This allowed the author to summarize the general state of the system of training student-teachers in Great Britain and Russia; to determine the modern society' requirements for student-teacher training challenging the higher educational institutions of Great Britain and Russia; to thoroughly analyze exemplary practices to meet these challenges; to bridge the British and Russian systems of training student-teachers at schools to fast-track Russia's joining the "European educational space". Equally appealing to general public the paper is of special interest for state and independent higher educational institutions and schools, organizations and individuals involved in training and supporting the student-teachers worldwide.
\end{abstract}

Keywords: teacher training, innovation, school-based education, European educational space, Russia, Great Britain

\section{Introduction}

\subsection{Background}

The teacher-training system in the Russian Federation as part of the international educational space is undergoing constant change, modernization and reform. The basis of this change is established with innovative projects of different levels, the most important of which are aimed at restructuring and intensification of teacher-training system. In the context of reforms the emphasis is placed on the school as the primary unit of change to ensure the further professional development of teachers. In the context of the intensification strategic state intervention in teacher-training is celebrated: it is viewed in standardization, restructuring of knowledge; setting the new challenges, focusing on the competence as a result and the resources necessary to meet the challenge (Novikov, 2000; Belyakov, 2007).

Innovations in teacher-training system are treated by the author in their most important dimension, in particularly, as a core of development. Their implementation is a multifaceted and ambiguous process of change (Sabirova, 2009). Thus, the generation of new teacher-training models takes place at the junction of controversial areas of unification and diversification; striving for innovative teacher education takes place against the backdrop of expanding standardization in the higher education "industry". Besides, now more than ever the problem of the interrelation of national, regional and global programs is becoming crucial for the training of future teachers (Brazhnik, 2002). 


\subsection{Status of a Problem}

Government acts aimed at the development and improvement of teacher training; generation of recommendations for further reforms in the vocational teacher training at the national and international levels; large-scale research projects; changes in the social role of teachers in the ever-changing society; the need to find innovative approaches to teaching traditional subjects have issued the modernization of teacher education process.

The innovative future of teacher education is seen in the increasing role of the teacher as one of the central figures in an increasingly complex environment involved in scientific and technical progress, systematic focus on a human factor. There is a pattern of progressive complexity of the requirements to the teacher and, therefore, a need for the synchronous development of his/her training in the context of innovation (Coolahan, 2002). Here the object of on-going pedagogical dispute is the search of the answer to the problem: what is the teacher to be like? (Petty, 2004). According to the international scientists and education theorists, it is the one who is "thinking, knowledgeable, capable of professional reflection" (Humphreys, 1994).

At least $30 \%$ of knowledge and skills that teachers will teach in 10 years, still do not exist today. These data were presented at the conference on Teacher Education Policy in the European Union at the Beginning of the XXI Century (Policy Review, 2010). This predetermined the necessity of educating the Teacher of the third millennium, who must be able to lead his/her own professional activity in accordance with the requirements of the time, constantly improving his/her skills; who is prepared to change quickly and efficiently in response to external changes and challenges (Education, 2004; Polunina, 2006).

\section{Materials and Methods}

\subsection{Thematic Justification}

The theme of the paper is justified since bridging British and Russian systems of supporting student-teachers at schools the author fills the actual research gap in education theory and practice.

The similarity of the trends in the development of teacher education in the Western Europe and Russia reveals the need to review the current local systems in terms of building a unified strategy of teacher training on a global scale.

\subsection{Objectives of the Research}

The main objectives of the research presented in the paper are the following:

1) summarizing the general state of the system of training student-teachers at schools in Great Britain and Russia;

2) determining the modern society' requirements for student-teacher training and challenges of the higher educational institutions of Great Britain and Russia;

3) thoroughly analyzing exemplary practices to meet the gap;

3) bridging the British and Russian systems of school- based training student-teachers to fast-track Russia's joining the "European educational space".

\subsection{Methods of the Research}

The following theoretical methods were used to determine the solution of the research problems:

- descriptive method for collecting the information on the problem;

- analyzing, synthesizing and classification of the investigated material;

- the system oriented analysis of psychological and pedagogical research and practice literature on the problem;

- generalization of innovative pedagogical experience in training student-teachers in British and Russian schools.

Theoretical and methodological basis of the research were primarily works of advanced Russian researchers, professors and teachers, such as E. I. Brazhnik (2002), G. A. Andreeva (2003), O. N. Oleynikova (2003), L. K. Grebenkina (2000), A. M. Novikov (2000), A. In (2006), L. N. Polunina (2006), V. V. Bekyakov (2007), Yu. V. Maslov (2013) who have made an insightful study into the problems of supporting student-teachers in the Russian Federation. The study also includes the analysis of works of international authors on the theory and practice of successful introduction of future teachers into the profession, namely S. Brindley (1994), T. Humphreys (1994), J. Lambert (1994), A. Edwards (1995), M. Wilkin (1996), S. Capel (1998), B. Moon (1998), 


\section{J. Coolahan (2002), G. Petty (2004).}

\subsection{Factual Material of the Research}

The research is based on generalization of traditional and innovative experience in training student-teachers collected by the author within 20 years of careful research into the problems of teacher-training education in Europe and Russia. The analytical material is supported with the illustrations from the author's personal professional experience of working as a practice school teacher and a professor at Teacher-Training University for more than 20 years.

\section{Results}

\subsection{A Glimpse of Student-Training in the UK: Tradition and Change}

A most illustrative example to start with, the Department of Education at the University of Oxford, is located in 3 buildings of Victorian style in Norham Gardens, facing the University Park. The Department of Education is equipped with lecture halls, seminar and tutor classrooms, a library, and three classrooms with microcomputer systems. The total number of students is 170. The Department of Education provides training of teachers majoring in English, Mathematics, Modern Languages, Science, Geography and History. Basic teacher training lasts one year and is focused on the comprehensive school curriculum. In addition, there are ample opportunities for students to work on a variety of research projects in their major. To this end, various funds and foundations are involved.

The new teacher-training programme was planned by faculty of the Department of Education and comprehensive schools teachers of the county of Oxfordshire. A close connection of the Department of Education and the so-called "internship" schools governed by the local educational authorities in Oxfordshire, Wiltshire and Northamptonshire is a characteristic feature of the organization of the education process at the Department. The so called "basic" educational institutions under discussion are state-maintained comprehensive, mixed schools (Andreeva, 2003).

\subsubsection{Integration Course: Fruitful Interaction of School and University}

Such cooperation is reflected in the integrated course, taken at the university and at school. The course starts with a short period of orientation in the primary and secondary school, the closest to the student-teacher's place of living. Then follows a short introduction to the course, provided partly at the university and at school. The rest of the autumn semester and the first part of the spring semester make up joint or combined weeks, conducted by 3 days at the university, 2 days in the school. Most of the spring semester and the first part of the summer semester is school practice only.

The integrated course of practical training of student-teachers, carried out under the leadership of a mentor (an experienced teacher), a professional tutor (a subject teacher), a general tutor (a member of the university staff), a curriculum tutor (a member of the university staff), should not be viewed as mundane work in which the student-teacher is reduced to the trainee's copying of the mentor activities. The main focus of the organization of work is made on facilitating students to think critically about the consequences of their actions and, therefore, to choose the best option. This integrated course has two main components - the General Programme and the Professional Development Programme.

For example, the English Language Curriculum aims to help students to make a complex and multifaceted transition from a user of the English language with a degree to the level of an English teacher in the comprehensive school. Professional Development Program, in this case, helps to determine the compliance of the student's current knowledge of the language to the needs of his/her school students. Thus, they develop an optional route to improve the current situation and a road-map to gain competent training, master critical and creative thinking about the learning process (Capel, 1998).

\subsubsection{The English Language Major - A Successful Educational Network}

The English Language major is planned in close cooperation of the Department of Education and teachers of the county of Oxfordshire. In addition, certain links with the College of Westminster, which caters for continuous teachers' training have been established. The content of the program includes learning the basics of classroom management, a number of approaches to teaching language skills, English literature and most successful means of communication with students. According to the course managers "the aim is to bring up a new generation of English teachers who will confidently and skillfully meet the requirements of English language teaching in the 21st century" (Belyakov, 2007).

In addition to the peculiarities of teaching the English language, the General Programme is to include the most 
common challenges teachers face at school: personal, physical and social education; especially that of adolescents of 16-19 years old; children group interaction; sexual education and others - all from the point of view of an English teacher.

Among the elective courses offered to students there are the following: Drama, Education in the Developing Countries, Introduction to Teaching Drama in the Arts Classes, Teaching Play-Learn at School, Museum as a Source of Education, Basic Computer Course, and others.

The Vocational Training Diploma is granted based on the evaluation of the student's performance throughout the year. The assessment includes reviews of university and school teaching staff on the work of the student according to the following criteria: the student's professional competence, the student's teaching of his/her subject, the student's work on the Professional Development Programme, the student's written paper on the chosen topic, the student's self-evaluation feedback (Sabirova, 2014).

\subsection{Current Teacher-Training System in Russia: Fast-Tracking Innovation}

Aiming at bridging British and Russian teacher-training systems via collecting and analyzing the most successful models the author offers an example of the organization of classes for students majoring in Foreign Language Teaching at Kazan Federal University, Russian Federation. The use of innovative approaches and methods of teaching a foreign language can be illustrated with a workshop-lesson "Personally Speaking" based on the textbook "CAE Focus on Advanced English" (O'Connell, 1998). The workshop was developed by professors of the Department of European Languages and Cultures and the results were put into practice at the seminars.

In the workshop students of 2 academic groups are arranged in one group, led by 2 professors. There is a "target break" to make up pairs, consisting of representatives of both groups. Thus, initially it carries out the idea of "spontaneous and maximum true-to-life communication activity" (students receive badges with numbers that designate them a pair) (Brindley, 1994). It should be noted that the presence of two professors per class is not an accident. Based on their own designed sentences, mini-dialogues, using the active vocabulary of the unit under study, adjectives describing personality traits, both professors introduce exercises of the "imposed choice" type. The professors demonstrate the use of personalizing questions, draw personalizing conclusion. At this stage the teacher's flexibility is marked and determined as an ability to work with a small group, extended groups and pairs of students. To summarize this phase of the work the students make their own logical conclusions, easily derive definitions for the basic concepts of the lesson.

Among the innovative forms of exercise "social interaction" can be mentioned which is maintained in the form of "social, biographical bingo". The students are provided with facts, personal characteristics, observations of other students. In pairs, interviewing each other according to the information in the table, followed by a listening unit, the learners are asked to carry out the interpretation of table entries, using the active vocabulary of the lesson.

In the final phase, students turn their badges back to forth to determine their part in the situational role-playing game. It is called "Employment Agency" and is represented by General Manager, Personnel Department Officer, Psychologist, Personal Assistant, Unemployed Applicant for the vacant position of a TV Reporter or a Flight Attendant. In this context, "Job Interview" role-play appears a valuable form, especially for senior under-graduates. The participants are invited to sample list of questions; they rely on contents the table other students filled with the interpretation of personal characteristics, considering, however, their personal and professional attitude to the situation. The participants of "the interview" are supposed to put down the answers of "the applicants", then the discussion follows and General Manager is to make a "verdict."

Role-based communication, implemented in the students' role-play is carried out in accordance with the scenario, the distributed roles and the predetermined inter-role relationships. Creative role-based communication requires developed social skills of the participants, which are regularly practiced in social training. Speaking Interaction tasks are performed on ramp-up in a pyramid-like pattern - first in pairs, then in small groups, and finally by the whole group of students.

The use of this form of innovative teaching is making a significant contribution to the education of the students' ability of group problem-solving, careful and respectful attitude towards others, develops group interaction skills. At this stage the main methodological principle is learning through communication, which uses real-life situations with genuine networking, opinion-sharing and conclusion-drawing.

From the standpoint of the theory of management of educational process the professor ensures the organization of educational material in the way it provides training sufficient for the real-life communication, both in its direct and indirect forms (Maslov, 2013). 
In the feedback session of the workshop the future teachers usually conclude that a successful implementation of this technique requires of a teacher more time and effort to generate texts and dialogues, a set of exercises and handouts. But, on the one hand, the teacher builds his/her own Task and Exercises Bank that can serve good for many years, enhances his/her professional competence and, supposingly, feels happy with the fact that he/her successfully solves the main professional task - teaching communication in a foreign language. In addition, a positive emotional atmosphere that reigns in the communication-directed lessons boosts motivation and contributes to favorable working environment in class in general.

\subsubsection{Improving Future Teachers' Presentation Skills}

Advanced language speaking skills is a must for a foreign language teacher as speaking is a considerable part of his/her professional activity. In other words, these skills include knowledge and application of the basics of rhetoric, the ability to manage the audience, to make a desired impact on the class with his/her speech. In this sense, the course "Culture of Communication. Rhetoric" included in the State Educational Standard of Foreign Language Teaching major partially solves these problems. Having extensive content but limited lecture and practice class hours it provides a glimpse of theoretical and practical aspects of the discipline.

It is obvious the future teacher only benefits if he/she masters the following:

- the skill of making up and pronouncing rhetorical statements;

- the power of intonation patterns, voice setting and voice contact with the audience;

- the ability to present the accessible and interesting material logically;

- the ability to manage the audience, organize the debate, the dispute in a foreign language -

all viewed as an integral part of the professional competence of teachers of foreign languages.

It is understood that the above mentioned important professional qualities of a foreign language teacher are formed not only by the named discipline. The process of training of modern educational specialist is usually regarded as a holistic, multi-level, multi-faceted and diverse in content and methods.

It should be noted that the formation of professional competence of a teacher is also dependent on the successful cross-subject implementation. The targeted education process has great potential to ensure the unity and interrelation of didactic and methodical training of students.

One of the best areas in the educational process, developing an independent creative activity, extremely stimulating the acquisition and consolidation of knowledge, is no doubt Student's Independent Study Projects under the guidance of a professor (Petty, 2004).

As an example we can consider the possibility of teaching the skills of verbal communication in an English Speech Practice class for senior students majoring in Foreign Language Teaching. Students of this major are usually equipped with basic knowledge in psychological and pedagogical disciplines, methods of teaching a foreign language, Communication Culture, a set of elective courses in their major and have tested the knowledge and skills during the teaching practice. They are have also a reflective competence - an ability to perform reflexive processes in the course of their professional activity, fairly evaluate their own achievements, measure compliance and conformity of actions in terms of personal development and creative self-realization.

While studying, discussing and generalizing "Education in Life" and "Learning and Teaching" sections presented in the course book by V. D. Arakin students various gain possibilities for reflection (Arakin, 2006). As they progress through these lessons, students choose one of the suggested topics to develop and later defend their own project in a Public Speaking class. Facilitated by the professor but still independent student's work on a project including a set of individual, creative, problem-solving tasks to do and is alternated by continuous team feedback is crowned with the presentation of the project, opponency, team expertise, conclusions. Here is a sample list of selected topics for the Student's Independent Study Projects: Lesson Presentation, Lesson Planning, Lesson Management, Grouping Students, Educational Technology and Other Teaching Equipment, Assessing Student Progress, Reflection and Self- Evaluation, Good Learner Characteristics, Good Teacher Characteristics and others.

\subsubsection{Facilitating Future Teachers' Learning Independence and Continuous Development}

There is a number of non-standard forms of organization of classroom and extracurricular work which can significantly boost future teacher's learning independence.

One of these forms is the use of so-called "cognitive maps" or mind mapping. "Cognitive maps" are working, cogitative, creative reasoning tools. They are suitable as supports for collecting and organizing thoughts and 
self-planning, improving associative thinking, problem-solving and interviewing skills. This method was developed as a result of research in the field of neurophysiology.

According to the theory of hemispheres, developed by American scientists R. Sperry and R. Ornstein, interconnected work of both hemispheres of the brain opens up enormous creative potential. The basis of this visualization technology is transferring from traditional forms of recording ideas in strict linear order to voluntary associations, which are transformed into keywords, with initial relationships outlined (Prashnig, 1998). Selecting a keyword becomes visual, fits the mood, physical condition, interests and capabilities of speakers and, most importantly, serves as a good motive and a stimulus for further communication activities. Only with this approach to the problem full-fledged manifestation of future teachers, their abilities, their personality becomes possible. Application of the "cognitive maps" contributes to the development of monologue and dialogue speaking skills and stimulates students to actively participate in the conversation. For example, when working on the topics "New Challenges in Education" and "Learning and Teaching" from the above mentioned text-book by V. D. Arakin students-future foreign language teachers are invited to reflect and make up "a cognitive web" consisting of words and actions defining the concept of "communication" (Arakin, 2006).

Each member of the group offers his/her own version of a word with a detailed description of its role and place in ensuring communicationin a foreign language class. The selected words must reflect the different strategies and approaches to the maintenance of authentic communication in the classroom. At the end of the panel discussion, students name factors and strategies that promote or hinder authentic communication (as can be seen in Table 1).

Table 1. Panel discussion questionnaire

\begin{tabular}{ll}
\hline $\begin{array}{l}\text { Factors, approaches, strategies and attitudes that } \\
\text { encourage authentic communication }\end{array}$ & $\begin{array}{l}\text { Factors, approaches, strategies and attitudes that } \\
\text { hinder authentic communication }\end{array}$ \\
\hline Factor 1 & Factor 1 \\
Factor 2 etc. & Factor 2 etc. \\
\hline
\end{tabular}

As in other cases student's project work, guided by the professor but still maximum independent, presupposes fulfilling a set of creative, problem-solving tasks, accompanied by on-going feedback from the whole group, and is finished with the presentation of the project, team expertise and conclusions.

This type of collaboration is based on cooperation, the process of joint research and proving the idea is becoming a priority in the formation of social and cultural norms of communication of a future foreign language teacher, helps to streamline thoughts and idea to ensure the independent study planning. Having mastered the principles of considering the problem using the "cognitive web" technique, students will be able to use it in teaching career.

\section{Discussion}

However close the goals and commitments of teacher training in Britain and in Russia may seem there is a number of challenges the domestic educational system has to meet in order to successfully realize the ambition of integration into the European educational space.

Early XXI century is marked by intense technologization of all branches of the education system, connecting schools to the local and global information networks, the maintenance of electronic data banks, the development of interactive, distant IT-based forms of training, standardization of ICT use by teachers, etc. Under such conditions, information and communication become the main production forces, and the economy goes innovative. The concept of "innovation" bears a crucial meaning. An effective means of providing scientific, technical and socio-economic progress of computerization, that is, the continuous increase of scientific knowledge and other information in the workplace and public life, which requires well-established mechanisms for the collection, processing, distribution and use of information in a rapidly changing world.

The innovative transformation lays particularly high demands on the level of intrapersonal intelligence, theoretical knowledge and practical training of a foreign language teacher. He/she should be able to modify the educational process according to the personality of the pupil, to build their professional activities so that every learner could gain unlimited opportunities for self-development and demonstrate high performance in a combination of logical-mathematical, linguistic and interpersonal intelligence. 


\section{Conclusions}

In conclusion, one can say that awareness of the need to join the European integration process, the mandatory entry in the "European educational space" is an important aspect of the British and Russian educational policy. In the process of reforming teacher-training system in England, started in the mid-1970s and now updated with new offers of indigenous or partial transformation, a number of trends common to most Western European countries in the course of the "European educational reforms", can be noted. They are:

- strengthening the state control over teacher-training, a trend to centralize the development of curricula and courses;

- expansion of ideological education of teachers by giving priority to the Social Sciences, or other related courses;

- standardization of curricula and programs;

- organization of teacher-training in the higher education sector;

- more careful selection of applicants for teaching profession via maintaining an effective system of career guidance and recruitment;

- focus on the expansion of general education and methodical competence of future teachers;

- strengthening of psycho-pedagogical preparation of students-teachers;

- localization of operational authority to schools to improve the educational process;

- promoting teachers' participation in research projects and pilot programs;

- further improvement of professional skills;

- large-scale initiative on building "an effective school" and "an effective teacher" of the future.

Progressive trends in the development of vocational teacher education gradually find support in everyday practice of teacher-training institutions of the country. Among them:

- updating skills and expertise of an individual teacher;

- promoting the development of an individual's competence;

- personal improvement of a teacher;

- promotion of a teacher's career;

- implementation of central government reforms;

- assistance the development of schools;

- exchange of information and expert opinions;

- support for new teachers.

Thus, the central task of the post-graduate system of continuous teacher education should be considered as the provision of pedagogical support for a teacher's positive self-expression and finding his/her "self" to ensure the necessary conditions for the transformation of this process in the mode of self-development.

As part of the indicated approach the realization of the idea of "tutor support" of a novice teacher by more experienced teachers and supervisors gains a particular importance.

\section{Acknowledgement}

The work is performed according to the Russian Government Program of Competitive Growth of Kazan Federal University.

\section{References}

Andreeva, G. A. (2003). The development of higher teacher education in England: axiological aspect (1970-90s). (Doctoral dissertation). Kolomna.

Arakin, V. D. (2006). Practical course of the English Language. A text-book for students of higher educational institutions (5th ed.). Moscow.

Belyakov, V. V. (2007). The development of the post-graduate professional education under the conditions of globalization (Abstract of doctoral dissertation ). Sankt-Petersburg.

Brazhnik, E. I. (2002). Generation and development of integration processes in modern European education 
(Doctoral dissertation). Sankt-Petersburg.

Bridges, D. (Ed.). (1993). Developing Teachers Professionally. L.- N.Y.

Brindley, S. (1994). Teaching English (The Open University). London.

Capel, S. (1998). The transition from student teacher to newly qualified teacher: some finding. Journal of In-Service Training, 24(3), 393-409. http://dx.doi.org/10.1080/13674589800200060

Coolahan, J. (2002). Teacher education and the teaching career in an era of lifelong learning. Paris.

Education for a Sustainable Future: Commitments and Partnerships. (2004). UNESCO Publishing.

Edwards, A. (1995). Teacher education: partnerships in Pedagogy? Teaching and Teacher Education, 11(6), 595-609.

Eggleston, J. (1992). The challenge for teachers. London.

Grebenkina, L. K. (2000). Building the professional competence of the teacher in the continuous teacher-education system. Ryazan. 204 p.

Herne, S., Jessel, J., \& Griffiths, J. (Ed.). (2000). Study to teach: a guide to studying in teacher education. L.- N.Y. Humphreys, T. (1994). A different kind of teacher (2nd ed.). Dublin.

In, A. (2006). Competence-type approach to generating the system of quality assurance in continuous teacher education (Doctoral dissertation). Moscow.

Lambert, J. (1992). Induction of newly trained and appointed teachers. London.

Maslov, Yu. V. (2013). Creativity as means of development of post-graduate foreign language education. Herald of Chernigov National Linguistic University, Research in Education Series, 2, 183-186.

Moon, B. (1998). International perspectives on the initial education and training of teachers. London.

Novikov, A. M. (2000). Education in Russia in the new epoch: heritage paradoxes, development vectors. Moscow.

O'Connell, S. (1998). Focus on Advanced English: C.A.E. for the Revised Exam (2nd ed.). London.

Oleynikova, O. N. (2003). General trends of development and modern condition of professional education in the European Union. Kazan.

Petty, G. (2004). Teaching today. A practical guide (3rd ed).

Policy Review on Teacher Education for Inclusion: International documents, reports and projects. (2010). European Agency for Development in Special Needs Education, Brussels Belgium. Retrieved from https://www.european-agency.org/sites/default/files/TE4I-Policy-Review.pdf

Polunina, L. N. (2006). Teacher-training in the European countries: national priorities and integration in the context of Bologne process (Unpublished master's thesis). Tula.

Prashnig, B. (1998). The power of diversity. Wellington.

Sabirova, D. R. (2009). Ensuring quality of continuous teacher training in Great Britain. Doctoral dissertation. Kazan.

Sabirova, D. R. (2014). Continuous teacher education: quality assurance. Procedia - Social and Behavioral Sciences, 143, 243-246. http://dx.doi.org/10.1016/j.sbspro.2014.07.396

Wilkin, M. (1996). Initial teacher training. The dialogue of ideology and culture. L.-W.

\section{Copyrights}

Copyright for this article is retained by the author(s), with first publication rights granted to the journal.

This is an open-access article distributed under the terms and conditions of the Creative Commons Attribution license (http://creativecommons.org/licenses/by/3.0/). 